\title{
Use of Early Juvenile Zebrafish Danio rerio for In-Vivo Assessment of Endocrine Modulation by Xenoestrogens
}

Tarini P Sahoo* and A Oikari

Division of Environmental Science and Technology, University of Jyväskylä, Jyväskylä, Finland

\begin{abstract}
Reliable and cost-effective early-life stage (ELS) bioassays incorporating practical experimentation without compromising scientific relevance are crucial in chemical risk assessment. This study investigated the use of 20 dayspost-fertilization life stage (20dpfZF) of zebrafish Danio rerio to screen environmental chemicals known to be estrogenic in adult fish. Firstly, studies with key genes in steroidogenesis were conducted; the brain isoform of aromatase gene (cyp19a1b) being the most prominently expressed biomarker. Regulation of mRNA levels of molecular biomarkers, vitellogenin 1 gene (vtg1) and cyp19a1b were selected to assess the endocrine modulation by xenoestrogens, 17a-ethinylestradiol (EE2), 4-n-nonylphenol (NP), 4-t-octylphenol (OP) and bisphenol A(BPA). Groups of 20dpfZF ( $n=15)$ as three replicates were exposed to chemicals over a five-day period in aerated static setups. Exposure of 20dpfZF to sediment spiked with EE2 (nominal $3 \mu \mathrm{g} \mathrm{g}^{-1} \mathrm{dw}$ ) was also conducted to assess the sensitivity of this life-stage to sediment with estrogenic potency. Whole body homogenates of exposed juveniles showed the estrogenic potential of chemicals in the order: EE2 > OP > BPA > NP. Higher relative expression of cyp19a1b was noticed at lower ambient concentrations of EE2, although vtg1 showed more pronounced expression to it. The 20dpfZF responded in a dose-related way to sediment spiked with EE2, expanding its use as a general aquatic animal model. The suitability of 20dpfZF as an in vivo model, along with stable expression of reference genes was established. In addition to consistent expression pattern of key target genes on xenoestrogenicity, it serves as a practical screening model for the risk assessment of environmental chemicals and samples with estrogenic potential.
\end{abstract}

Keywords: Brain aromatase; Early-life stage; Vitellogenin1; Xenoestrogenicity; Zebrafish

\section{Introduction}

Diverse groups of natural and synthetic compounds known to have an endocrine bioactive potential are constantly introduced into the environment. These endocrine disrupting compounds (EDCs) have been found to exhibit significant effects on reproduction by acting on endocrine functions [1,2]. Given the extent of organic pollutants released into aquatic environment, teleosts among vertebrate taxa qualify as candidates to investigate endocrine modulation [2-6]. The choice of zebrafish Danio rerio (Hamilton, 1822) as a toxicological model presents practical advantages, including cost-effective maintenance, asynchronous breeding, and rapid development of the embryo-larval stages. Moreover, the sexual differentiation in the brain determining the fate of the gonads in teleosts, contrasts with amphibians and mammals [7]. In general, signaling cues in the form of endogenous hormones and external factors stimulate the pituitary to release gonadotropins, which in turn stimulate the gonads to synthesize and release endogenous hormones, sex steroids. Under endocrine control, the hypothalamuspitutary-gonadal (HPG) axis is further extended to the liver (HPGL), the site for synthesis of the precursor of yolk protein, vitellogenin $(V t g)$, common to oviparous vertebrates. The hepatic synthesis of these proteins is stimulated by the binding of physiological estrogens or xenoestrogens to estrogen receptors (ERs) in the liver (Figure 1). In zebrafish, seven isoforms of $v t g$ have been identified, with dominant expression of $v \operatorname{tg} 1$ compared to $v \operatorname{tg} 2-7$ [8]. Males possessing the normally unexpressed $v t g$ genes when exposed to exogenous estrogen or their mimics, up-regulate vitellogenesis [1]. Consequently, alteration of endocrine signaling along the HPGL axis and subsequent modulation of gametogenesis and other reproductive processes from teleost responses indicates mechanisms of EDC action [9].

Bio-chemical pathways have been used to link health and reproductive status in wildlife to environmental chemical exposures. Steroid biosynthetic enzymes catalyze the conversion of cholesterol into active sex hormones (estradiol and testosterone) mainly in brain, kidney and gonads [10]. Key enzymes in steroidogenesis include steroidogenic acute regulatory (Star) protein, cytochrome P450 side-chain cleavage (P450scc) or Cyp11a1, 3-beta-hydroxysteroid dehydrogenase (Hsd3b1), and cytochrome P450 aromatase (P450arom) or Cyp19a1 (Figure 1). Other studies have also discussed regulation in the steroidogenic pathway with gene expression analyses with adult fathead minnow [11] and zebrafish (in vitro, [12]; in vivo, [13,14]. Immunohistochemical studies showed the significance of (endogenous) sex steroids on gonadal sex differentiation in teleosts $[9,15]$. Other studies did not support the involvement of endogenous steroids in the gonadal sex differentiation in fish species such as medaka [16]. Therefore, it was interesting to compare in this study the expression patterns of key steroidogenic enzymes in early juvenile zebrafish, if any. Importantly, the synthesis and release of sex steroids is controlled by the aromatization of C19 androgens (testosterone) to C18 estrogens (17 $\beta$-estradiol) by aromatase. In teleosts, the expression of tissuespecific isoforms of P450arom genes (gonad, cyp19a1a; brain, cyp19a1b) [17], with significantly higher relative expression of the brain isoform, has been used to indicate estrogenic stimulation of sex steroid synthesis [18-23]. Besides induction of $v \operatorname{tg} 1$, alterations of steroid biosynthesis and plasma steroids are biomarkers indicative of estrogenic action [24].

*Corresponding author: Tarini Prasad Sahoo, Division of Environmental Science and Technology, University of Jyväskylä, Jyväskylä, 40014, Finland, Tel: 358408053900; Fax : 358142602321 ; E-mail: tarini.sahoo@jyu.fi

Received October 21, 2013; Accepted December 24, 2013; Published December 27,2013

Citation: Sahoo TP, Oikari A (2013) Use of Early Juvenile Zebrafish Danio Rerio for In-Vivo Assessment of Endocrine Modulation by Xenoestrogens. J Environ Anal Toxicol 4: 202. doi: 10.4172/2161-0525.1000202

Copyright: $\odot 2013$ Sahoo TP, et al. This is an open-access article distributed under the terms of the Creative Commons Attribution License, which permits unrestricted use, distribution, and reproduction in any medium, provided the original author and source are credited. 


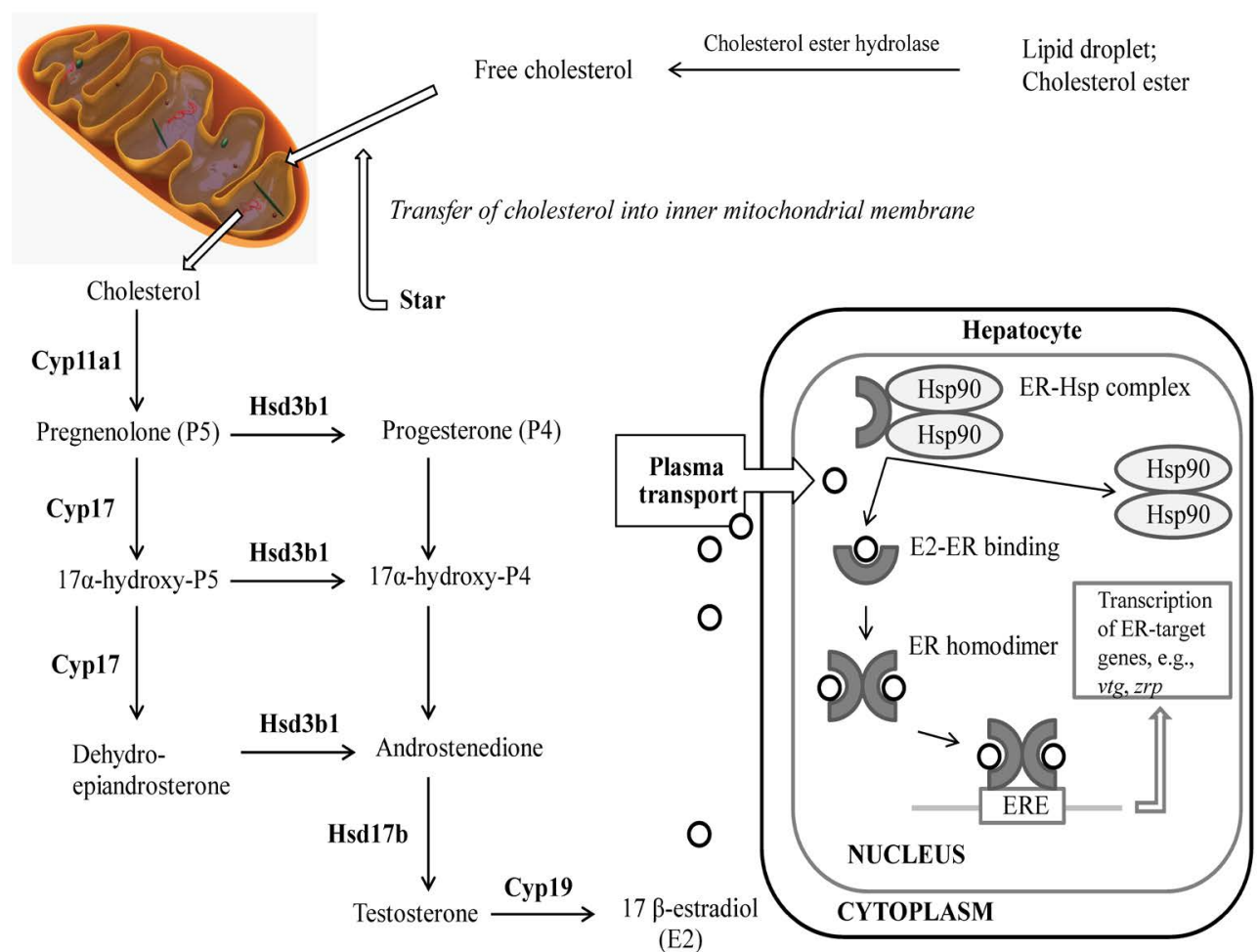

Figure 1: An outline of the steroid biosynthetic pathway and the action of estrogen on vitellogenesis in fish and other vertebrates. The conversion of cholesterol to pregnenolone and subsequent steps occurs in the inner mitochondrial membrane. Homodimerization of ERs and binding to estrogen-responsive elements $(E R E)$ in the regulatory region (promoter) of susceptible genes lead to transcription of estrogen-responsive genes.

Along with $v t g 1$, gene expression of cyp19a1b, a central steroidogenic enzyme, present suitable molecular markers to detect and analyze the impact of estrogenic exposure, considering the short ovarian cycles and estrogen-responsive embryonic stages in zebrafish. The postembryonic life-stage (20 days-post-fertilization zebrafish; $20 \mathrm{dpf} Z F$ ) was used for a five-day exposure to 17a-ethinylestradiol (EE2), a common benchmark of xenoestrogens. Although ranging in nano-and micromolar concentrations in ambient water $\left(0.2-40.0 \mathrm{ng} \mathrm{L}^{-1}\right.$; [25]) and sediment $\left(<0.5-22.8 \mu \mathrm{g} \mathrm{kg}^{-1}\right.$ dry mass; [26]) sources respectively, EE2 is a potent xenoestrogen known to have adverse effects on the endocrine function of aquatic organisms.

The objective of this study was to evaluate a life-stage incorporating practical and experimental advantages for screening environmental estrogens, assessed by gene expression analyses. Pilot exposures to EE2 were carried out to select the key steroidogenic enzyme, cyp19a1b to complement $v \operatorname{tg} 1$ as a panel of estrogen-responsive biomarkers for subsequent studies. Besides EE2, the sensitivity of this life-stage was evaluated with water-borne exposures of other xenoestrogens with varying potencies-bisphenol A (BPA), $4-n$-nonylphenol (NP) and 4-tert-octylphenol (OP). The screening potential of $20 \mathrm{dpfZF}$ was also verified with exposure to sediment spiked with EE2, and is discussed in context to regulatory requirements with the use of adult animals in toxicological research.

\section{Materials and Methods}

\section{Chemicals and exposure stock solution}

2,2-bis(4-hydroxyphenyl)propane (BPA 17a-ethynyl,3,5(10)-estratriene-3, 17 $\beta$-diol (EE2, minimum $98 \%$ by HPLC), and 4-(1,1,3,3-tetramethylbutyl)phenol (OP, 97\%) were purchased from Sigma-Aldrich (St. Louis, MO, USA). 4-n-Nonylphenol (NP, 98+ \%) was obtained from Alfa Aesar (Karlsruhe, Germany). Silylation reagent N, O-bis(trimethylsilyl) trifluoroacetamide (BSTFA) with $1 \%$ trimethylchlorosilane (TMCS) was purchased from Fluka Chemie (Buchs, Switzerland). Internal standards 17- $\alpha$-ethynylestradiol-d4 (EE2-d4, 97-98\%) and 2,2-bis(4hydroxyphenyl) propane-d16 (BPA-d16, 98\%) were purchased from LGC Standards AB (Borås, Sweden). The solvents, methanol $(\mathrm{MeOH})$ and acetonitrile, supplied by Merck Chemicals (Darmstadt, Germany) were of HPLC grade. Separate chemicals were dissolved in methanol, and stocks were stored at $-20^{\circ} \mathrm{C}$ until use, within two weeks.

\section{Experimental animals}

Adult male and female zebrafish (Danio rerio) (wild type; WT) were obtained from Institute of Medical Technology, University of Tampere (Tampere, Finland). Fish were acclimatized to temperatures (mean \pm standard deviation, $26 \pm 1^{\circ} \mathrm{C}$ ) and photoperiod ( $14 \mathrm{~h} \mathrm{light} / 10 \mathrm{~h}$ dark) for at least two weeks prior to setup for breeding. Animal husbandry was carried out along established guidelines (Westerfield, 2007). Zebrafish adults were fed twice daily with frozen chironomid larvae (Ruto frozen fish food, Zevenhuizen, Holland). Following breeding between sexually mature adults ( $\sim 8$ month old), fertilized eggs $(0.5-$ 1.5 hours-post-fertilization; hpf) were collected and reared through early post-embryonic stages for 20 days (20dpfZF) in rearing water or embryo medium (Westerfield, 2007). Post-hatch zebrafish from $6 \mathrm{dpf}$ through $25 \mathrm{dpf}$ were fed with fry food (SDS diets, UK). 


\section{Chemical exposure and sampling}

Chemical exposures were conducted in glass jars containing 250 $\mathrm{mL}$ of exposure medium, consisted of gently aerated embryo-rearing water ( $\mathrm{pH}$ 7.2) for the duration of the experiment, to avoid change in water quality. Water-borne exposures (I and II) were carried out in a semi-static manner, replacing $100 \%$ of the medium daily. Water quality parameters were measured on days 1 and 4 . The mean temperature in the exposure jars was in the range $24-26^{\circ} \mathrm{C}$. The content of dissolved oxygen $\left(\mathrm{DO}, \mathrm{mg} \mathrm{L}^{-1}\right.$ ) was $7.6 \pm 0.2$ (mean $\mathrm{DO} \pm \mathrm{sd}$ ) and $\mathrm{pH} 7.2 \pm 0.2$ (mean \pm sd). Chemicals dissolved in the carrier solvent, methanol $(\mathrm{MeOH})$, were administered to the exposure water, the solvent concentration being $0.02 \%$ or less. Preliminary exposures also included water controls (data not shown), i.e., without solvent to confirm similarity with that of the maximum solvent concentration $(0.02 \%)$. The first set of exposures (Exposure I) were performed with groups of 30 fish $(20 \mathrm{dpfZF})$, replicated three times in parallel, exposed to $0.02 \% \mathrm{MeOH}$ with $0,5,25$ and $50 \mathrm{ng}$ EE2 $\mathrm{L}^{-1}$, to determine expression and selection of suitable of steroidogenic gene(s). The second set of exposures (Exposure II) were performed with groups of 25 fish $(20 d p f Z F)$, replicated three times, exposed to $0.02 \% \mathrm{MeOH}$ with $0,5,25$, and $50 \mathrm{ng} \mathrm{EE} 2 \mathrm{~L}^{-1}, 0,100,500$, and $1000 \mu \mathrm{g} \mathrm{BPA} \mathrm{L}{ }^{-1}, 0,10,50$, and $100 \mu \mathrm{g} \mathrm{NP} \mathrm{L}{ }^{-1}$, and $0,10,50$, and $100 \mu \mathrm{g}$ $\mathrm{OP} \mathrm{L}^{-1}$. Although the results used in discussion represent measurement from three parallel replicates, the pattern of relative expression of target genes were also verified with two independent exposures conducted earlier. Fish were sampled at the end of five days of exposure. Each group of sampled animals $(\mathrm{n}=15)$ was collectively weighed in rnasefree micro centrifuge tubes (Starlab, Germany), and snap-frozen in liquid nitrogen and stored at $-80^{\circ} \mathrm{C}$ until further analysis. Experiments were conducted according to and licensed by the Finnish authority for animal experiments (ESAVI-2010-07885/Ym-23).

\section{Sediment exposure}

The reference sediment $(0-10 \mathrm{~cm}$ depth; dry weight, dw 5.2\%; total organic content, TOC $4.7 \%$ ) was sampled from Lake Palosjärvi (located in Central Finland) using an Eckman grab sampler. Chemical spiking of it was performed according to standard guidelines for wholesediment toxicity testing $[27,28]$. Briefly, nominal concentration $3 \mu \mathrm{g} \mathrm{g}^{-1}$ dw of EE2-spiked sediment was prepared by gradually administering EE2 (dissolved in $100 \%$ methanol) to sediment slurry with minimum amount of water mixed for $\sim 7 \mathrm{~h}$. Following the addition of EE2, the headspace of sample container was filled with an inert gas $\left(\mathrm{N}_{2}\right)$ and sealed for equilibration at $4^{\circ} \mathrm{C}$ for a minimum of $30 \mathrm{~d}$ before the assays. The exposure series (Exposure III) were prepared in $600 \mathrm{~mL}$ glass beakers in a ratio $1: 4(\mathrm{dw} / \mathrm{v})$ of sediment and overlying water $\left(3^{\circ} \mathrm{dH}\right.$ or $54 \mathrm{mg} \mathrm{CaCO}_{3} \mathrm{~L}^{-1}$ ), added slowly to avoid any suspension of particulates to the water column. The exposure beakers were allowed to stand for $\sim 16 \mathrm{~h}$ at $24-26^{\circ} \mathrm{C}$ before the experimental fish $(\mathrm{n}=25)$ were added. The exposure series consisted of control sediment (Ref-Sed; i.e., the reference Palosjärvi sample) compared with EE2-spiked samples; Sed $1(3 \mathrm{~d})$, and Sed $2(5 \mathrm{~d})$. The exposures of animals were conducted in aerated static systems (no water renewal), sampled at the end of $3 \mathrm{~d}$ for Ref-Sed, Water-EE2 (150 ng L $\left.{ }^{-1}\right)$, Sed 1+ Salt and Sed 1, and at the end of $5 \mathrm{~d}$ for Sed 2 (Figure 4). Two controls treatments, each accompanying the respective 3 - and $5 \mathrm{~d}$ exposures were included to provide for relative quantification per sampling time point. To maintain the water quality, the fish were not fed during the experiment. To assess the possible role of the influence of electrolyte content of overlying water, another sediment exposure Sed $1+$ Salt included E3 salts (embryo medium; $6^{\circ} \mathrm{dH}$ or 107 $\mathrm{mg} \mathrm{CaCO} \mathrm{L}^{-1}$ ) at levels used for rearing of embryo-larval stages of zebrafishup to 20dpfZF. For comparison of estrogenic effects, water- borne exposure of $20 \mathrm{dpfZF}$ to $150 \mathrm{ng} \mathrm{EE} 2 \mathrm{~L}^{-1}$ for $3 \mathrm{~d}$ was also included as positive control. Experimental conditions and fish sampling $(n=3$ pools of at least 15 fish each) was the same as in water-borne exposures.

\section{Solid-phase extraction (SPE) of water samples}

Ethinylestradiol was extracted from water samples by a SPE method [29] modified for the analyses in the present study (see supplementary information). Similar extraction was employed with NP and OP samples (3-10 mL) using BPA-d16 as the internal standard.

\section{GC-MS analysis of EE2}

The gas chromatography-mass spectrometry (GC-MS) was performed with HP 6890 gas chromatograph (Hewlett-Packard, Walbronn, Germany) equipped with HP 5973 mass selective detector (Hewlett-Packard, Palo Alto, CA, USA). The method included a derivatization [30] by silylation with BSTFA, and pyridine to increase the stability of derivatized products and improve extraction recoveries of the target compounds (see supplementary information). Concentration of EE2 was calculated using relative spectral peak-areas of analytes, internal standard, and the determined response factor. Specifically, the results were based on determination of di-TMS derivatives of EE2 and EE2-d4.

\section{LC-MS /MS analysis of BPA, NP, and OP}

The analysis was performed with Waters Alliance 2795 (MA, USA) LC and the determination of target compounds was performed in negative ion electro spray mode (ESI-) and a Quattro Micro triplequadrupole mass spectrometer (MS/MS) (Waters, MA, USA) with electro spray interface was used as detector. The method described by Revilla-Ruiz et al. [31], with minor modifications, was conducted with extracted (NP and OP) and un-extracted (BPA) water samples. Data acquisition was performed with multiple reactions monitoring (MRM) mode and the corresponding parameters for the target compounds are presented in supplementary (Table SI).

\section{Isolation of RNA and reverse transcription}

Total RNA was extracted from homogenized pooled fish samples (15 animals with total weight ca. $16 \mathrm{mg}$ ) using the Tri Reagent (Molecular Research Center, Inc.) according to manufacturer's instructions, and the quality and quantity were determined on a NanoDrop ND-1000 UV-visible spectrophotometer. Absorbance measurements including 260:280 ratios (1.8 to 2.0) and the additional 260:230 > 260:280 ratios indicated a secondary measure of nucleic acid purity [32]. The integrity of RNA was also verified using the Agilent RNA 6000 Nano Assay Protocol with an Agilent 2100 Bioanalyzer (Waldbronn, Germany). RNA integrity number (RIN, 1-10) generated for analyzed samples was checked within range 7-10 for all samples. The total RNA extracted was reverse transcribed into cDNA using iScript cDNA synthesis kit (BioRad, USA), and the cDNA templates were diluted ten times for use in real-time PCR assays.

\section{Real-time PCR}

Real-time PCR was performed using iQ SYBR Green supermix (Bio-Rad, USA) and run on a Bio-Rad CFX96 ${ }^{\mathrm{TM}}$ real-time PCR detection system (Bio-Rad, USA). Gene-specific primers (Table SII) for housekeeping genes (beta-actin ( $\beta$-actin) and elongation factor 1 alpha (efla)) as well as target genes (star, cyp11a1, hsd3b1, cyp19a1b) were designed using Amplifx (v 1.5.4), and the given oligonucleotides (desalt purified) were purchased from Sigma-Aldrich (UK). The primer pair sequences were checked with the program Mfold (http://mfold.bioinfo.rpi.edu/ 
cgi-bin/dna-form1.cgi) to predict the potential for amplicon secondary structures that may prevent efficient amplification. To evaluate qPCR efficiency, amplification efficiency with standard curve analysis (PCR efficiency, $90-110 \%$; slope, -3.1 to -3.6 ; $\mathrm{R}^{2}>0.98$ ) was performed, and optimization of qPCR reactions and protocol was carried out. The qPCR reaction mix was optimized for a $25 \mu \mathrm{L}$ reaction mix consisting of $12.5 \mu \mathrm{L}$ of SYBR green supermix, $2.5 \mu \mathrm{L}$ of each of the primer pairs

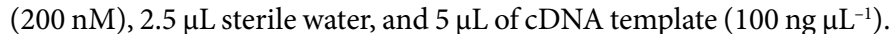
The PCR protocol comprised $10 \mathrm{~min}$ polymerase activation at $95^{\circ} \mathrm{C}$, followed by $40 \mathrm{cycles}$ of $30 \mathrm{sec}$ at $95^{\circ} \mathrm{C}$, and $30 \mathrm{sec}$ at $60^{\circ} \mathrm{C}$. Each sample was assayed in duplicate, and assays requiring multiple runs included inter-run calibrators (IRCs) on each of the plates to facilitate sample maximization and restricting reference gene reactions to a single plate. The inter-run calibration was performed to correct for variation, allowing comparison between plates within the same analysis.

\section{Data analysis}

The expressions of target genes were normalized to the expression of two reference genes, ( $\beta$-actin, ef1a). The choice of reference genes was based on their stable expression across samples of different treatment. The determined stability parameter ( $M$ value) for the reference genes were used to select suitable reference genes with $\mathrm{M}$ values $<0.5$; the lower the $\mathrm{M}$-value, that higher the stability [33]. The relative gene expression levels were calculated from the experimental amplification data $(\mathrm{Cq}$ values; quantification cycles) using the $2^{-\Delta \Delta C T}$ method [34]. Statistical significance $(\mathrm{P}<0.05)$ of log-transformed data from Exposures I and III was determined by a one-way analysis of variance (ANOVA) followed by Tukey HSD post hoc test. Data from Exposure II was analyzed using Welch's test followed by Games-Howell post hoc test. All analyses were performed using IBM SPSS (v 19).

\section{Results}

\section{Water quality and concentrations of xenoestrogens in experiments}

No significant difference in water quality was found between exposure jars or treatments during the exposure period. Regarding to nominal concentration added in experimental waters, actual chemical concentrations (mean $\pm \mathrm{sd}$ ) are presented in Table SIII. However, all measured concentrations of NP were not detected. Since both NP and OP samples were extracted simultaneously with the same method, the undetected NP samples may have resulted from issues with the extraction method. For clarity, while the measured concentrations commonly ranged $20-50 \%$ below expected, revealing effects, the nominal values are used in further discussion.

\section{Exposure I: Responses of steroidogenic enzyme mRNA levels}

The mean M-values of reference genes, $\beta$-actin and ef1 $a$ across the corresponding concentration series of exposures (BPA, NP, OP, and EE2) were 0.004, 0.1, 0.3, 0.06; and 0.01, 0.04, 0.06, 0.09 respectively, showing stable expression of the respective housekeeping genes. For normalization of gene expression, the mean $\mathrm{M}$-values of both reference genes combined and considered together for the chemical exposures were $0.01,0.07,0.06$, and 0.07 respectively, suggesting the stable expression of this reference gene pair across chemical treatment at the studied life-stage.

Figure 2 shows the normalized gene expression levels of cyp11a1, cyp19a1b, hsd3b1, and star in 20dpfZF exposed to EE2 for five days (20$25 \mathrm{dpf}$ ). Among the studied genes, only cyp $19 a 1 b$ showed pronounced expression levels compared with cyp11a1, hsd3b1, and star, (Tukey
HSD, $\mathrm{P}<0.001)$. Noticeable induction of cyp $19 a 1 b$ resulted formal EE2 exposures $\left(5,25\right.$ and $\left.50 \mathrm{ng} \mathrm{L}^{-1}\right)$, averaging $13.5,18.7$ and 22.8 -fold changes respectively, with gradual increase with increasing concentrations (5-50 ng $\left.\mathrm{L}^{-1}\right)$. In preliminary studies with similar experimental conditions, cyp19a1b showed $\sim 2$-fold increase at even lower exposures $\left(1 \mathrm{ng} \mathrm{L}^{-1}\right)$ (data not shown). There was no induction of star in exposure groups, with expression even in the highest EE2 exposure, $50 \mathrm{ng}$ EE2 $\mathrm{L}^{-1}$, being similar with that of control and $5 \mathrm{ng}$ EE2 $\mathrm{L}^{-1}$. Although $25 \mathrm{ng}$ EE2 $\mathrm{L}^{-1}$ revealed $\sim 1.3$-fold change, the altered star expression was not significantly different from either the control or respective expression levels of cyp11a1 and $h s d 3 b 1$ (Tukey HSD, P > 0.05). Similarly, no statistically significant effects were observed with the mRNA levels of cyp11al and $h s d 3 b 1$ that actually showed decreased average expression compared to solvent control. Overall, there was a statistically significant difference between expression of $c y p 19 a 1 b$ and the other steroidogenic enzymes (star, cyp 11al and $h s d 3 b 1$ ) as determined by one-way ANOVA for EE2 exposures $5 \mathrm{ng} \mathrm{L}^{-1}(F(3,8)=91.740, \mathrm{P}<0.001), 25 \mathrm{ng} \mathrm{L}^{-1}(F(3$, $8)=61.130, \mathrm{P}<0.001)$ and $50 \mathrm{ng} \mathrm{L}^{-1}(F(3,8)=133.082, \mathrm{P}<0.001)$. A Tukey HSD post hoc test revealed the significant up-regulation of only cyp19a1b expression among the studied steroidogenic enzymes $(\mathrm{P}<0.001)$ compared to star-cyp11a1 $(\mathrm{P}=0.848)$ and star-hsd3b1 $(\mathrm{P}=0.982)$.

\section{Exposure II: Changes in cyp19a1b and vtg1 mRNA levels to xenoestrogens in water}

Figure 3a shows the relative expression of cyp19a1b and $v \operatorname{tg} 1$ in $20 d p f Z F$ exposed to EE2 from 20 through 25 dpf. The mRNA levels of cyp19a1b exposed to 5, 25, and $50 \mathrm{ng}$ EE2 $\mathrm{L}^{-1}$ were induced to 13, 19 , and 24 -fold respectively, relative to control treatment. For the same concentrations, relative expression levels of $v \operatorname{tg} 1$ were 5, 143, and 1272fold. Despite the larger extent of $v \operatorname{tg} 1$ expression across the exposure treatment, cyp 19a1b showed more sensitive induction (13-fold; GamesHowell, $\mathrm{P}<0.05)$ at the lowest range (5ng EE2 $\mathrm{L}^{-1}$ ) compared to $v$ tg1 (5fold; Games-Howell, $\mathrm{P}<0.05$ ). As presumed, the pattern of expression of $c y p 19 a 1 b$ at all concentrations of EE2 was similar to samples studied for steroidogenic enzyme mRNA levels (Figure 2d); with gradual increase from 5 to $50 \mathrm{ng}$ EE2 $\mathrm{L}^{-1}$. However, at higher treatments levels ( 25 and $50 \mathrm{ng} \mathrm{EE2} \mathrm{L}^{-1}$ ), the relative induction of $v \operatorname{tg} 1$ (Games-Howell, $\mathrm{P}<0.01,0.001$ ) was noticeably higher than cyp19a1b (Games-Howell, $\mathrm{P}<0.05$ ), albeit both the genes showing significant relative expression. Almost $15 \%$ mortality was observed in groups exposed to the highest nominal concentration of EE2 (Figure S1).

Whole-body cyp19a1b showed increased expression levels at 100 , 500 and $1000 \mu \mathrm{g} \mathrm{BPA} \mathrm{L}{ }^{-1}$ compared to $v \operatorname{tg} 1$ (Figure 3b). Expression of $v t g 1$ was down-regulated (in average -1.2-fold change) by lower concentrations of BPA (100 and $\left.500 \mu \mathrm{g} \mathrm{L}^{-1}\right)$, but was significantly upregulated at the highest concentration (2.7-fold change; Games-Howell, $\mathrm{P}<0.05)$. The two higher concentrations of $\mathrm{BPA} \mathrm{L}^{-1}$ showed significant induction of cyp19a1b transcripts, 2.9 and 4.4-fold (Games-Howell, $\mathrm{P}<0.05)$ respectively. Clearly, cyp19a1b was more sensitive compared to $v t g 1$ across a range of BPA exposures, further revealing that BPA induces a weak estrogenic effect when compared to EE2.

In $20 d p f Z F$ exposed to 10,50 and $100 \mu \mathrm{g} \mathrm{NP} \mathrm{L}^{-1}$, the relative expression levels of both cyp19a1b and $v \operatorname{tg} 1$ showed no statistically significant change (Games-Howell, $\mathrm{P}>0.05$ ), showing a clear downregulation for both genes (Figure $3 \mathrm{~b}$ ). Compared to NP, the expression pattern was different with OP exposure; cyp19a1b showing an upregulatory pattern for all three concentrations compared to control (Figure $3 \mathrm{~b}$ ). The relative induction of $v \operatorname{tg} 1$ was significant only at 100 

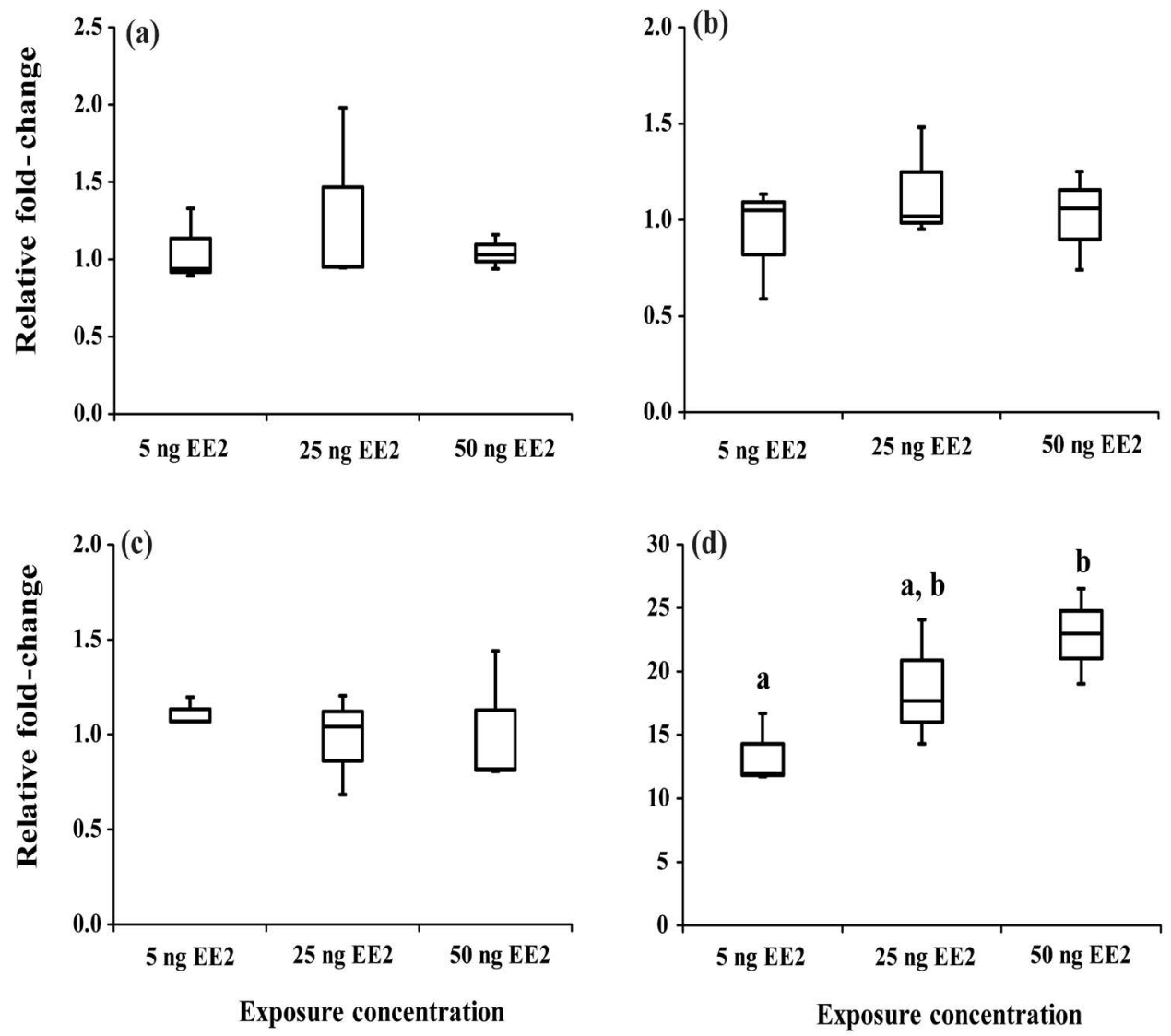

Figure 2: Exposure I: Changes in mRNA levels of steroidogenic enzymes. Gene expression of star (a), cyp11a1 (b), hsd3b1 (c) and cyp19a1b (d) in $20 d p f Z F$ exposed to concentrations of EE2 for five days (from 20 to $25 \mathrm{dpf}$ ). Box plots represent median (-), 25th and 75 th percentiles (lower and upper end of boxes) minimum and maximum values (end of the whiskers) for polled whole-body homogenates ( $\mathrm{n}=3$ pools of at least 20 fish each). Target genes were normalized to

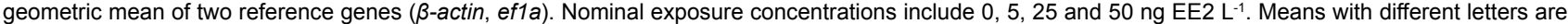
significantly different $(\mathrm{P}<0.05)$ as determined by One-way ANOVA followed by Tukey's HSD post hoc test.

$\mu \mathrm{g} \mathrm{OP} \mathrm{L} \mathrm{L}^{-1}$ (2.5-fold; Games-Howell, $\left.\mathrm{P}<0.05\right)$. For all the concentrations, cyp19a1b again showed higher sensitivity for the induction, i.e., 1.9, 1.7 , and 2.5-fold. With OP, as in the case of EE2 and BPA, cyp19a1b was a more sensitive biomarker of estrogenicity than $v \operatorname{tg} 1$. Overall, it is noteworthy that NP compared to EE2, BPA, and OP had a much less estrogenic effect in the $20 d p f Z F$ model. There was statistically significant difference between exposure groups determined by Welch's test for both cyp19a1b $(F(11,9.197)=422.008, \mathrm{P}<0.001)$ and $v \operatorname{tg} 1(F$ $(11,9.355)=666.860, \mathrm{P}<0.001)$. Both 50 and $100 \mu \mathrm{g} \mathrm{OP} \mathrm{L}{ }^{-1}$ affected the survival of exposed fish to 20 and $30 \%$ mortality (Figure S1).

\section{Exposure III: Changes in cyp19a1b and $v \operatorname{tg} 1 \mathrm{mRNA}$ levels to sediment spiked with EE2}

In relevant contexts of in vivo exposures, 20dpfZF showed preferential use of water-column depending on exposure type (with and without sediment). While each group of 25 animals in the wateronly units appeared to distribute randomly across the water column, the fish in units with sediment headed for the sediment-water interface, perhaps seeking food. Actually, by actively ingesting contaminated sediment, the possibility to study diverse exposure scenarios with $20 d p f Z F$ (i.e. contaminants taken up by ingestion) was obvious (Figure $5 b)$. We suggest that the same is not possible with sessile and nonfeeding life stages.
One-way ANOVA analysis of normalized gene expression showed significant induction of both cyp19a1b $(F(4,10)=1096.501, \mathrm{P}<0.001)$ and $v \operatorname{tg} 1(F(4,10)=2471.846, \mathrm{P}<0.001)$ of $20 d p f Z F$ when exposed to sediment spiked with nominal $3 \mu \mathrm{g}$ EE2 $\mathrm{g}^{-1} \mathrm{dw}$ over three to five days (Figure $4 \mathrm{a}, 4 \mathrm{~b}$ ). Between the exposures (Sed1 and Sed2) conducted over three and five days, Tukey's HSD post hoc test showed that fish exposed to sediments with EE2 exhibited higher induction of $c y p 19 a 1 b$

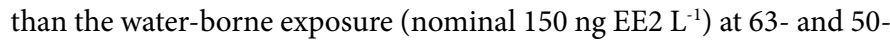
fold change, respectively (Figure 4a). Significant up-regulation of Sed 2 fish with 74-fold change, compared to EE2-water exposure, indicated the influence of the extended exposure duration. For the $3 \mathrm{~d}$ exposures (Sed1+Salt, Sed1), which differed only in respect to the electrolyte content, showed higher induction (72-fold) compared to that of Sed1, although not significantly different (Tukey's HSD, $\mathrm{P}=0.473$ ).

The expression of $v \operatorname{tg} 1$ showed very pronounced up-regulation patterns, increasing from EE2 in water (181-fold) to Sed 1 (500-fold) and Sed 2 (1152-fold) (Figure 4b). Unlike cyp19a1b, vtg1 showed significantly lower induction in Sed $1+$ Salt (198-fold) when compared to Sed 1 (500-fold), possibly as an indication of the difference in the fraction of EE2 taken up by the fish (Tukey's HSD, $\mathrm{P}<0.001$ ). These may be considered consistent with differences in the partitioning and bioavailability of EE2 between static water and sediment exposures systems, based on ambient characteristics. 


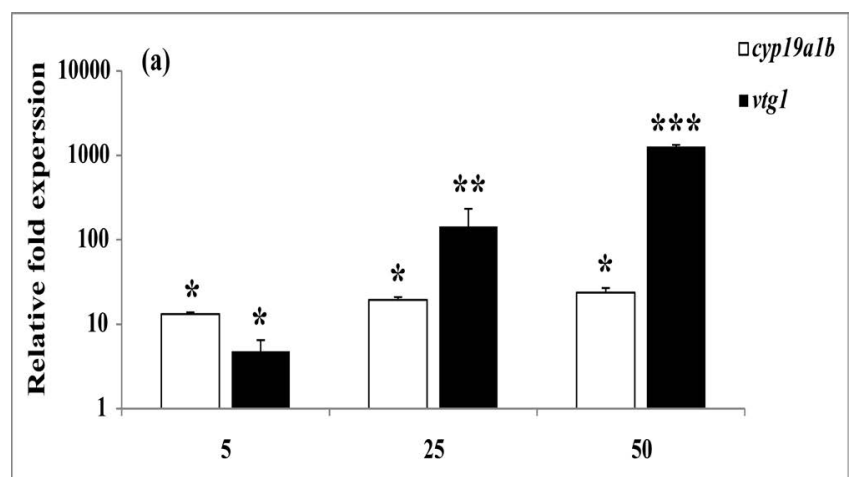

EE2 (ng $\left.\mathrm{L}^{-1}\right)$ exposure concentration

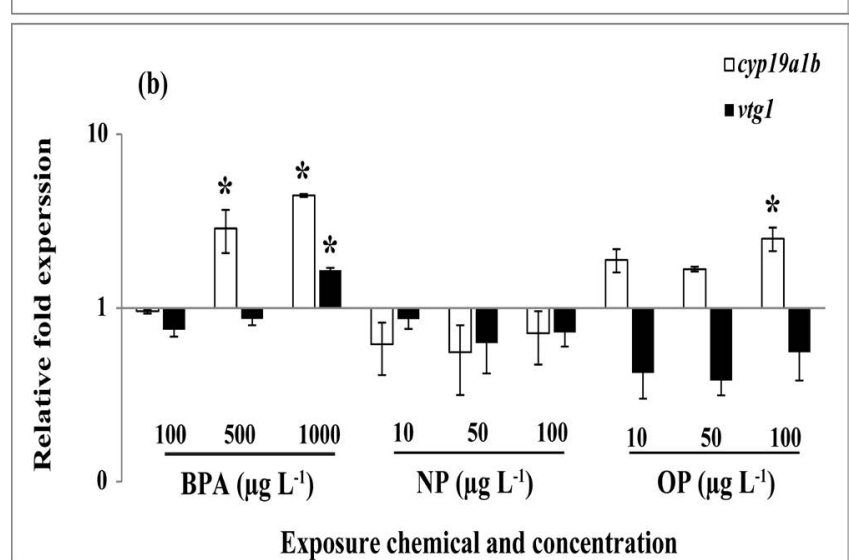

Figure 3: Exposure II: Xenoestrogen-induced gene expression in 20dpfZF. Fold-change expression ofcyp19a1b andvtg1 in 20dpfZF exposed to three nominal concentrations of EE2 (a), BPA, NP and OP (b) for five days, i.e., over the period $20-25 \mathrm{dpf}$, in a whole-body assay. Bars represent gene expression fold-change ( \pm SD; $n=3$ pools of 15 fish each) normalized to geometric mean of $\beta$-actinand ef $1 \mathrm{a}$ and relative to solvent $(0.01 \%$ methanol) control. The expression levels are in log10 scale. Note expression of both cyp19a1b and vtg1 genes were down-regulated in NP exposure (b). The asterisks represent statistically significant differences, ${ }^{*} P<0.05,{ }^{* *} P<0.01$ and ${ }^{* *} P<0.001$ as determined by Welch's test followed by Games-Howell post hoc test.

\section{Discussion}

Among aquatic vertebrates, the zebrafish has been widely applied in investigating biological responses in development [35], endocrine disruption [3,4,36], and reproduction [37] among other effects. As adult organisms, the fish has been established as a reliable and sensitive organism in studies of comparative toxicology. On the other hand, in line with alternative animal testing requirements, ELS bioassays are aimed to substitute more advanced stages for toxicity testing [37-39]. The feasibility to expose ELS includes a large sample size, not possible with adult fish. Moreover, an early in vivo model presents an integrated organism system compliant with regulatory mandates of vertebrate animal testing. The reliability of gene level responses [40,41], including estrogenic and the other steroidogenic ones, is suggested to give a mechanistic understanding on impacts of environmental chemicals, their dynamics of effects, and most importantly, extrapolations used in environmental risk assessment. Introduction of the $20 d p f Z F$ clearly satisfied several scientific, practical, and cost-effective requirements, although the main focus of this study was to select and evaluate the life-stage as a suitable screening model for xenoestrogenicity. The information regarding the gene-level response determined here in water-based exposures could be compared to a sediment exposure carrying a potent xenoestrogen with substantial trait of hydrophobicity, EE2 $\left(\log \mathrm{K}_{\text {ow }} 4.15\right)[42]$.

Exposure of zebrafish (20-25 dpf) to EE2, BPA, NP, and OP was used to evaluate regulation of $c y p 19 a 1 b$ and $v t g 1$ transcript levels. The choice of cyp19a1b as a core endpoint for this life-stage was determined from concentration-specific transcript abundance compared to other steroidogenic enzymes (star, cyp1la1 and $h s d 3 b 1$; Figure 1). The presence of ERE in the promoter region of cyp19a1b, but absent on cyp19a1a, has been shown to explain the estrogen-responsiveness of cyp19a1b $[7,18,43]$.

\section{Exposure I: Selection of steroidogenic endpoint for xenoestrogenicity}

The steroid biosynthetic pathway can be a susceptible target because of its key enzymes, each capable of setting off a cascade of events. For instance, in adult zebrafish exposed to water-soluble fraction of crude oil, Arukwe et al. [13] demonstrated a negative relationship between altered steroidogenic responses and xenobiotic biotransformation processes. The same study showed down-regulation of important steroidogenic enzymes including star and cyp11a1, and up-regulation of $h s d 3 b 1$ along with increasing contaminant level. Levi et al. [14] showed hepatic expression of star in non-vitellogenic female zebrafish. In the present study we found no change of star mRNA levels except some tendency for down-regulation relative to the control group at exposure levels 5 and 25 ng EE2 L ${ }^{-1}$ (Figure 2a). Filby et al. [11] also showed down-regulation of star mRNA in adult male fathead minnow exposed to $10 \mathrm{ng} \mathrm{EE} 2 \mathrm{~L}^{-1}$ but no significant changes in exposed females. In vitro cultures of zebrafish ovarian follicles at different maturation stages exposed to human chorionic gonadotropin revealed an increase in expression of star, cyp1lal and hsd3b1 with mature stages, in contrast with a decreasing pattern without exposure [12]. In this study, the mRNA levels of cyp11a1 and $h s d 3 b 1$ were relatively lower for all exposure concentrations with lowest relative expression for $25 \mathrm{ng}$ EE2 $\mathrm{L}^{-1}$ at $59 \%$ and $45 \%$ respectively (Figure $2 \mathrm{~b}$ ). Lower expression levels of star, cyp11a1, and hsd3b1 in fish exposed to EE2, a potent agonist for estrogenic effects, suggest effective regulatory processes in effect. In comparison to three other transcripts, cyp19a1b showed a clear dose-specific up-regulation pattern. Filby et al. [11] that showed upregulation of only cyp19a1a but not cyp19a1b in male fathead minnow exposed to EE2, possibly owing to the pronounced expression of the brain isoform (cyp19a1b) in earlier life-stages. The use of cyp19a1b signal has also been employed in transgenic zebrafish specifically as estrogenic-sensitive screens $[44,45]$. Because cyp19a1b is a key player in steroid biosynthesis at stage of $20 \mathrm{dpfZF}$, involved in conversion of androgen to estrogen, it qualified as a compelling signature of xenoestrogen-induced effects.

\section{Exposure II: cyp19a1b and $v \operatorname{tg} 1 \mathrm{mRNA}$ regulation by four potential xenoestrogens}

In the present study, modulation of cyp19a1b and vtg1 mRNA expression was used as biomarker for estrogenic effect in the identified responsive ELS of zebrafish (Figure 3). Earlier, in mature adults, estrogen-mediated expression of $c y p 19 a 1 b$ has been described among other teleosts, e.g. in Atlantic salmon [46], mangrove killifish [47], medaka [48], and zebrafish [18-20]. Expression of cyp19a1b in developing zebrafish (3-4dpf) was shown to be a sensitive indicator of estrogen-induced effects even earlier than 20dpfZF [49]. Giving further support to our research, Muncke and Eggen [50] described the induction of $v \operatorname{tg} 1 \mathrm{mRNA}$ as a reliable endpoint for 1-5 dpf zebrafish, presenting alternatives for adult animal testing. 

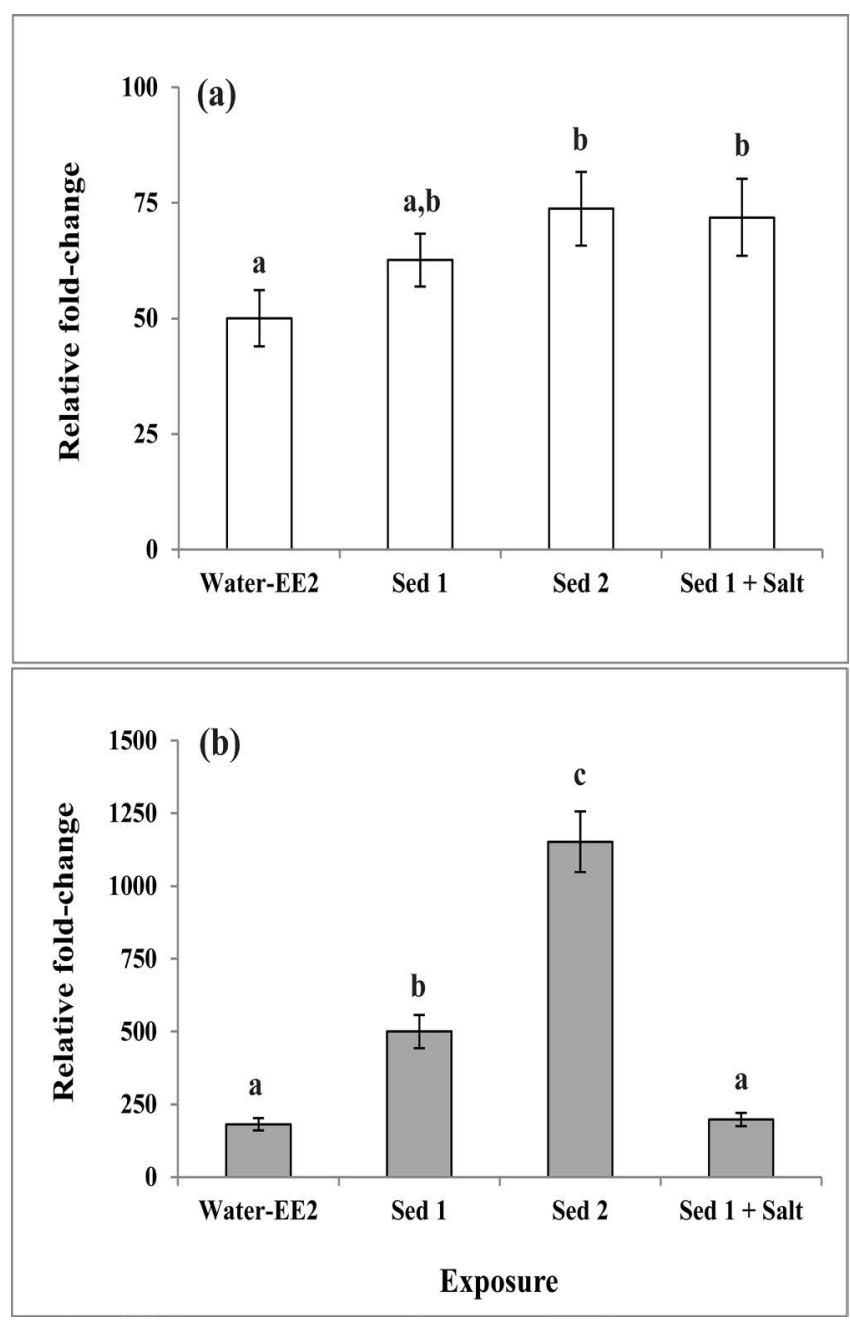

Figure 4: Exposure III: Gene induction caused by sediment-borne EE2. Foldchange of cyp19a1b (a) and $v \operatorname{tg} 1$ (b) from whole body homogenate of early juvenile zebrafish (23-25 dpf) exposed to sediment spiked with EE2. Fish ( $\mathrm{n}=3$ pools) were sampled at the end of $3 \mathrm{~d}$ for Ref-Sed, Water-EE2 (150 ng L-1), Sed $1+$ Salt and Sed 1 and at the end of $5 \mathrm{~d}$ for Sed 2. Bars represent normalized gene expression expressed as fold-change relative to control or reference exposure (Ref-Sed). Values are mean \pm SD (15 fis triplicate pool). Means with different letters are significantly different $(P<0.05)$ as determined by One-way ANOVA followed by Tukey's HSD post hoc test.

Our juvenile zebrafish (20 dpf) exposed to EE2 showed inductions of cyp $19 a 1 b$ and $v \operatorname{tg} 1$ in a concentration-dependant manner, $v \operatorname{tg} 1$ being more distinct than cyp19a1b. Importantly, however, the expression levels of cyp19a1b were increased in all exposure groups relative to control, serving as an excellent benchmark. For comparison, in adult male zebrafish exposed to EE2 for three weeks, induction of cyp19a1b mRNA [51] and protein levels [4] were also evident. Our data with 20dpfZF showed around 13-fold cyp19a1b induction at nominal concentration of $5 \mathrm{ng}$ EE2 $\mathrm{L}^{-1}$ and more at higher concentrations, keeping with range of expression in adults. Even somewhat younger animals than in our study, $17 \mathrm{dpf}$ zebrafish exposed from 0.3 to $30 \mathrm{ng} \mathrm{L}^{-1} \mathrm{EE} 2$ showed statistically significant induction in a dose-dependent manner in three days [19,52]. Although significant induction of $v \operatorname{tg} 1 \mathrm{mRNA}$ was observed in very early zebrafish embryos

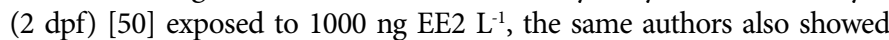
significant up-regulation of $v$ tg1 mRNA in zebrafish embryos exposed to $25 \mathrm{ng} \mathrm{L}^{-1}$ for $5 \mathrm{dpf}$ [41].
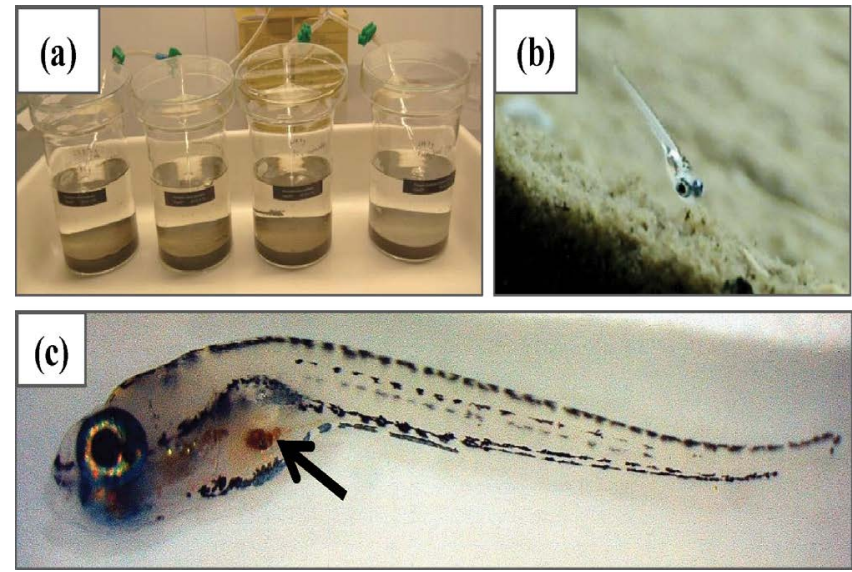

Figure 5: Experimental setup of sediment assay (Exposure III) over 5 day exposure period (a). Free swimming juvenile zebrafish (20-25 dpf) foraging on particulate matter in upper most sediment layer (b). Arrow indicates ingested sediment in accumulated in the gut of fish (body length, $7.8 \mathrm{~mm}$ ) at the end of exposure (c).

In $20 d p f Z F, c y p 19 a 1 b$ was up-regulated in a concentrationdependent manner above $500 \mu \mathrm{g} \mathrm{BPA} \mathrm{L}{ }^{-1}(\mathrm{P}<0.05)$ and $v t g 1$ at 1000 $\mu \mathrm{g}$ BPA $\mathrm{L}^{-1}(\mathrm{P}<0.05)$. While in adult fish the induction of Vtg has been documented well [4], post-hatched and early juvenile zebrafish exposed to BPA for $5 \mathrm{~d}$ induced $v \operatorname{tg} 1$ at higher concentrations, $2280 \mu \mathrm{g} \mathrm{BPA}$ $\mathrm{L}^{-1}$ [41]. Our results showed sensitivity of $20 \mathrm{dpfZF}$ exposed to 1000 $\mu \mathrm{g} \mathrm{BPAL}^{-1}$, comparable with adult male zebrafish exposed for three weeks that showed lowest observed effect concentration (LOEC) for vitellogenin protein induction for similar exposure concentration [4]. Thereby, the estrogenic responses of $20 d p f Z F$ present a cost-effective life-stage compared to the adult fish as well as further developed metabolic capacity when compared to embryonic stages.

Unlike BPA, NP showed clear down-regulation of estrogenic response in 20dpfZF. This is in contrast to significant effects observed in adult $[4,53]$ as well as larval [54] stages of zebrafish and other small bodied fish models, Japanese medaka [55] and fat head minnow [56]. However, other studies this far with zebrafish embryos exposed to NP showed no significant induction of $v \operatorname{tg} 1$ mRNA [36,41], indicating low sensitivity to the chemical. Our results confirmed the low sensitivity of juvenile life-stages to NP as shown by Jin et al. [36]. It also contrasts with the significant induction of aromatase by juvenile zebrafish (17 dpf) exposed to NP for 3d [52]. In our study, the mRNA of both cyp19a1b and vtg1 were down-regulated. In essence, the observed discrepancies can be related to the difference in composition of the selected chemical. Previous studies [4,54] with NP included a technical grade of NP (CAS 84852-15-3); a mixture of isomers. In our study, the linear form of 4- $n$-NP (CAS 104-40-5) that is devoid of branched alkyl side-chains present in most of the isomers, showed slightly reduced estrogenic potency (relative to E2), compared to the higher efficacy of technical grade NP [57]. From metabolite studies of $4-n$-NP in fish, biotransformation pathway involving $\beta$-oxidation of the alkyl sidechain results in metabolites, lacking the alkyl side-chain, which largely accounts for the lesser estrogenic potential of $4-n$-NP in vivo [58].

Among the three alkylphenols in the present study, only OP significantly induced $v \operatorname{tg} 1$ in $20 d p f Z F$. Earlier studies with adult zebrafish showed the weak estrogenic potential of OP at similar concentrations as used by us [4]. Thus, considering the differences in sensitivity between 
life stages, the dose-dependent induction of both $v \operatorname{tg} 1$ and cyp19a1b observed in $20 d p f Z F$ is indicative of a suitable window to predict xenoestrogenicity as the key biomarker. It presents a viable and costeffective life-stage to assess all related chemicals with weak estrogenic potential. In all, from the exposure series with $20 d p f Z F$, a clear ranking of the estrogenic potency was obtained, with EE2 being the most potent agonist, followed by OP, BPA, and $4-n-\mathrm{NP}$ in that order.

\section{Exposure III: cyp19a1b and vtg1 mRNA regulation by sediment spiked with EE2}

Gene induction data from the sediment assay with spiked EE2 indicated applicability and distinct sensitivity of the $20 \mathrm{dpfZF}$ in in vivo bioassays (Figure $4 \mathrm{a}$ and $4 \mathrm{~b}$ ). Due to its physicochemical properties $\left(\log \mathrm{K}_{\mathrm{ow}}=4.15 ; \log \mathrm{K}_{\mathrm{oc}}=3.8\right.$; sorption constant, $1 / n=0.83$; sorption coefficient, $\log \mathrm{K}_{\mathrm{f}}=1.72$ ) [42], EE2 was understood to have sorbed to the sediment that consequently acts as a sink for the sediment-water interactions. While the vtg1 gene expression as shown in Exposure I (Figure 3) indicating the pronounced potency of EE2 even at $50 \mathrm{ng} \mathrm{L}^{-1}$ to produce nearly 1400 -fold change, a reduced effect was seen in the water-borne exposure to $150 \mathrm{ng} \mathrm{EE} 2 \mathrm{~L}^{-1}$, the positive control (Figure $4 \mathrm{~b})$. This can be explained by the static nature of the water-only exposure without renewal of media. Thereby the exposure via water in the static system would result in decline of available EE2 in water phase. Thus the exposure scenario was probably different. In the sediment acting as a sink, thereby partitioning EE2 to water phase to maintain its concentrations towards the sediment-water equilibrium of EE2, was taken up by the fish. Of the two biomarkers, $v t g 1$ was more sensitive than cyp 19a1b to sedimental EE2 and indicative even of some influence of electrolyte content in overlying water on the availability of EE2 (Figure $4 \mathrm{a}$ and $4 \mathrm{~b}$ ). Mechanistically, as EE2 in Sed 1+ Salt exposure was sorbed to the sediment matrix to a greater extent than in Sed 1, the lesser EE2 content in the aqueous phase consequently elicited a lower induction of vtg1 (Figure $4 \mathrm{~b}$ ). Considering the same sediment characteristics (TOC $\%$, particle size, spiking, sample preparation) for both samples with the sole exception of overlying water quality (Sed $1+$ Salt; $0.3 \% \mathrm{NaCl}$, $107 \mathrm{mg} \mathrm{CaCO}_{3} \mathrm{~L}^{-1}$ ), this explanation is consistent with studies on the effect of salinity on the higher or lower sorption of EE2 to sediment as shown by Lai et al. [42]. Although, the role of electrolyte content on bioavailability of EE2 can be empirically verified with wide ranges of salinity and hardness levels, this was outside the scope of our study. Moreover, the difference in overlying water was included in our study only to determine variation in biomarker response because E3 salts are generally added in ELS rearing media. While the current trials to assay sediment with $20 d p f Z F$ were first ones of its kind, we did not analyze the dynamics of EE2 content in either compartment. Anyways, in presenting expected responses, the relevancy of $20 \mathrm{dpfZF}$ in sediment bioassay does exist. For further goals, data generated with $20 \mathrm{dpf} Z F$ can be employed to study various joint effects of multi-component xenoestrogens.

\section{Choice of suitable developmental stage of zebrafish for evaluation of estrogenicity}

Maturity is not the only important life-stage for reproductive success and population maintenance. In support of the relevance of ELS in manifestation of toxicity, age-specific developmental factors, including chorion-permeability and the nutrition by yolk associated with embryonic life as well as post-hatched eleuthero embryos, define important ontogenic stages. There is a common notion that newly post-hatched embryos are the most or equally sensitive life-stage of oviparous fishes to environmental chemicals [19,37,59]. This said, the rule includes several minor exceptions, which in part directed our study to the early post-yolk stages of zebrafish. While several rangefinding exposures with various ages of zebrafish to xenoestrogens were examined at large sub-lethal range, a decision was made to focus on $20 d p f Z F$ based on the survivorship as well as consistency of response levels of genomic regulation associated with the life stage. Furthermore, the combined advantages of an ELS that is both free-swimming and free-feeding (Figure 5b), but also cost-effective in terms of husbandry efforts compared to later or adult stages. The life stage was found to be practical and responsive to different media, including here the exposure to EE2-spiked sediment as a contact assay (Figures $5 \mathrm{~b}$ and $5 \mathrm{c}$ ).

Regarding xenoestrogenicity of chemicals, the time frame for ontogenic determination of the phenotype in juvenile life can be considered significant. In zebrafish, an undifferentiated gonochorist, ovary-type gonad in the juvenile hermaphrodite stage (21dpf) is transformed into distinct sex-specific mature gonads (42 dpf), leading to phenotypic sex differentiation [60]. At 20-25 dpf, the fish are developmentally more advanced than embryonic stages. However, the possibility of detecting signals from presumptive females from a pool of samples fish is addressed with normalized gene expression quantified relative to control treatments. With as large a sample size (15-25 fish) as in this study, statistically significant difference of estrogenic gene expression between exposures highlights the reliable detection of a genomic signal. Advancement in existing estrogen-sensitive screening has employed the induction of green fluorescent protein expression in transgenic zebrafish, cyp19a1b-GFP [44,45] and ere-zvtg1:gfp [61], pointing to non-lethal alternatives of animal testing. Chen et al. [61] showed GFP induction in transgenic zebrafish represented by less than $25 \%$ of the exposed fish. Sex differentiation in fish, known to be controlled by various environmental as well as of endogenous (steroidogenic) factors, is supported by the role of sex-steroids on differentiation and phenotypic outcome [62]. More specifically, the modulation of aromatase and vitellogenin, both key players in the onset of endogenous estrogen action, can be directly linked to gonadal sex differentiation from endocrine disruptors $[63,64]$. The choice of a labile life-stage taking into consideration such biological events, directs to the $20 d p f Z F$ as a suitable ELS model for investigating endocrine modulation.

In conclusion, we documented that the post-embryonic (20dpfZF) zebrafish was a potent life-stage using transcripts of cyp19a1b and $v t g 1$ as endpoints to assess xenoestrogenicity of chemicals. The RTPCR presented analytical tools to evaluate xenoestrogenic modulation in a relatively quick approach. The $20 d p f Z F$ life-stage provided for cost-effective maintenance and experimentation (compared to adult fish), and responded to four model estrogens with varying potencies characterized by corresponding induction patterns. The results of this study recommend the selection of $20 d p f Z F$ as a representative life-stage for use in ongoing and further studies, including exposures to watersediment interactions and mixtures of environmental chemicals.

\section{Ackonwledgements}

We thank E-R. Vehniäinen, M. Lahti and T. Heinonen for their keen interest and technical support in analytical issues. We also thank the anonymous reviewers whose comments and suggestions helped improve the manuscript. This project was conducted under the collaboration of University Alliance Finland and cooperation with the Cell Research Centre, Medical School at University of Tampere, Finland Funding was also provided by the Academy of Finland (109823). 
Citation: Sahoo TP, Oikari A (2013) Use of Early Juvenile Zebrafish Danio Rerio for In-Vivo Assessment of Endocrine Modulation by Xenoestrogens. J Environ Anal Toxicol 4: 202. doi: 10.4172/2161-0525.1000202

\section{References}

1. Sumpter JP, Jobling S (1995) Vitellogenesis as a biomarker for estrogenic contamination of the aquatic environment. Environ Health Perspect 103 Supp 7: 173-178.

2. Kime DE (1998) Disruption of hypothalamic and pituitary function. In: Endocrine Disruption in Fish. Kluwer Academic, London.

3. Segner H, Navas JM, Schäfers C, Wenzel A (2003) Potencies of estrogenic compounds in in vitro screening assays and in life cycle tests with zebrafish in vivo. Ecotoxicol Environ Saf 54: 315-322.

4. Van den Belt K, Verheyen R, Witters H (2003) Comparison of vitellogenin responses in zebrafish and rainbow trout following exposure to environmental estrogens. Ecotoxicol Environ Saf 56: 271-281.

5. Kidd KA, Blanchfield PJ, Mills KH, Palace VP, Evans RE, et al. (2007) Collapse of a fish population after exposure to a synthetic estrogen. Proc Natl Acad Sci U S A 104: 8897-8901.

6. Scholz S, Mayer I (2008) Molecular biomarkers of endocrine disruption in small model fish. Mol Cell Endocrinol 293: 57-70.

7. Diotel N, Le Page Y, Mouriec K, Tong SK, Pellegrini E, et al. (2010) Aromatase in the brain of teleost fish: expression, regulation and putative functions. Fron Neuroendocrinol 31: 172-192.

8. Wang H, Tan JT, Emelyanov A, Korzh V, Gong Z (2005) Hepatic and extrahepatic expression of vitellogenin genes in the zebrafish, Danio rerio. Gene 356: 91-100.

9. Devlin RH, Nagahama Y (2002) Sex determination and sex differentiation in fish: an overview of genetic, physiological, and environmental influences. Aquaculture 208: 191-364.

10. Payne AH, Hales DB (2004) Overview of steroidogenic enzymes in the pathway from cholesterol to active steroid hormones. Endocr Rev 25: 947-970.

11. Filby AL, Thorpe KL, Maack G, Tyler CR (2007) Gene expression profiles revealing the mechanisms of anti-androgen- and estrogen-induced feminization in fish. Aquat Toxicol 81: 219-231.

12. Ings JS, Van Der Kraak GJ (2006) Characterization of the mRNA expression of Star and steroidogenic enzymes in zebrafish ovarian follicles. Mol Reprod Dev 73: 943-954.

13. Arukwe A, Nordtug T, Kortner TM, Mortensen AS, Brakstad OG (2008) Modulation of steroidogenesis and xenobiotic biotransformation responses in zebrafish (Danio rerio) exposed to water-soluble fraction of crude oil. Environ Res 107: 362-370.

14. Levi L, Pekarski I, Gutman E, Fortina P, Hyslop T, et al. (2009) Revealing genes associated with vitellogenesis in the liver of the zebrafish (Danio rerio) by transcriptome profiling. BMC Genomics 10: 141

15. NakamuraM, Kobayashi T, Yoshiura Y, Nagahama Y (2000) Role of endogenous steroid hormones on gonadal sex differentiation in fish. In: Proceedings of the Sixth International Symposium on the Reproductive Physiology of Fish. Bergen, Norway.

16. Kawahara T, Yamashita I (2000) Estrogen-Independent Ovary Formation in the Medaka Fish, Oryzias latipes. Zoolog Sci 17: 65-68.

17. Tchoudakova A, Callard GV (1998) Identification of multiple CYP19 genes encoding different cytochrome P450 aromatase isozymes in brain and ovary. Endocrinology 139: 2179-2189.

18. Callard GV, Tchoudakova AV, Kishida M, Wood E (2001) Differential tissue distribution, developmental programming, estrogen regulation and promoter characteristics of cyp19 genes in teleost fish. J Steroid Biochem Mol Biol 79 : 305-314

19. Kazeto Y, Place AR, Trant JM (2004) Effects of endocrine disrupting chemicals on the expression of CYP19 genes in zebrafish (Danio rerio) juveniles. Aquat Toxicol 69: 25-34.

20. MenuetA, Pellegrini E, Brion F, Gueguen MM, Anglade I, et al. (2005) Expression and estrogen-dependent regulation of the zebrafish brain aromatase gene. $J$ Comp Neurol 485: 304-320.

21. Le Page Y, Scholze M, Kah O, Pakdel F (2006) Assessment of xenoestrogens using three distinct estrogen receptors and the zebrafish brain aromatase gene in a highly responsive glial cell system. Environ Health Perspect 114: 752-758.
22. Hinfray N, Palluel O, Turies C, Cousin C, Porcher JM, et al. (2006) Brain and gonadal aromatase as potential targets of endocrine disrupting chemicals in a model species, the zebrafish (Danio rerio). Environ Toxicol 21: 332-337.

23. Zucchi S, Blüthgen N, leronimo A, Fent K (2011) The UV-absorbe benzophenone- 4 alters transcripts of genes involved in hormonal pathways in zebrafish (Danio rerio) eleuthero-embryos and adult males. Toxicol App Pharmacol 250: 137-146.

24. Karels A, Markkula E, Oikari A (2001) Reproductive, biochemical, physiological, and population responses in perch (Perca fluviatilis L.) and roach (Rutilus rutilus L.) downstream of two elemental chlorine-free pulp and paper mills. Environ Toxicol Chem 20: 1517-1527.

25. Barel-Cohen K, Shore LS, Shemesh M, Wenzel A, Mueller J, et al. (2006) Monitoring of natural and synthetic hormones in a polluted river. $\mathrm{J}$ Environ Manage 78: 16-23

26. Lópezde Alda MJ, Barceló D (2001) Use of solid-phase extraction in various of its modalities for sample preparation in the determination of estrogens and progestogens in sediment and water. J Chromatogr A 938: 145-153.

27. Westerfield M (2007) The Zebrafish Book: A guide for the laboratory use of zebrafish (Daniorerio). University of Oregon Press, Portland, OR.

28. ASTM (1998) Standard guide for designing biological tests with sediments E1525-94a. In: Annual Book of ASTM Standards 11 Philadelphia, PA.

29. Waters Corporation (2008) Endocrine disruptors- General SPE guidelines. In Oasis sample preparation, Applications notebook. Waters Corporation, USA 35

30. Zhang ZL, Hibberd A, Zhou JL (2006) Optimisation of derivatisation for the analysis of estrogenic compounds in water by solid-phase extraction gas chromatography-mass spectrometry. Anal Chim Acta 577: 52-61.

31. Revilla-Ruiz P, Kearney G, McMillan D, Rodriguez-Gonzalo E (2007) A sensitive method for the determination of endocrine-disrupting compounds in river water by LC/MS/MS. In: Environmental Applications Book, Waters Corporation. Milford, USA.

32. NanoDrop Technologies (2007) $260 / 280$ and $260 / 230$ ratios, NanoDrop® ND 1000 and ND-8000 8-sample spectrophotometers. Technical support bulletin T009.

33. Vandesompele J, De Preter K, Pattyn F, Poppe B, Van Roy N, et al. (2002) Accurate normalization of real-time quantitative RT-PCR data by geometric averaging of multiple internal control genes. Genome Biol 3: RESEARCH0034.

34. Livak KJ, Schmittgen TD (2001) Analysis of relative gene expression data using real-time quantitative PCR and the 2(-Delta Delta $\mathrm{C}(\mathrm{T})$ ) Method. Methods 25 : 402-408.

35. Hill AJ, Teraoka H, Heideman W, Peterson RE (2005) Zebrafish as a mode vertebrate for investigating chemical toxicity. Toxicol Sci 86: 6-19.

36. Jin Y, Chen R, Sun L, Qian H, Liu W, et al. (2009) Induction of estrogenresponsive gene transcription in the embryo, larval, juvenile and adult life stages of zebrafish as biomarkers of short-term exposure to endocrine disrupting chemicals. Comp Biochem Physiol C Toxicol Pharmacol 150: 414-420.

37. Brion F, Tyler CR, Palazzi X, Laillet B, Porcher JM, et al. (2004) Impacts of 17 beta-estradiol, including environmentally relevant concentrations, on reproduction after exposure during embryolarval-, juvenile- and adult-life stages in zebrafish (Daniorerio). Aquat Toxicol 68: 193-217.

38. Trant JM, Gavasso S, Ackers J, Chung BC, Place AR (2001) Developmental expression of cytochrome P450 aromatase genes (CYP19a and CYP19b) in zebrafish fry (Danio rerio). J Exp Zool 290: 475-483.

39. Hollert H, Keiter S, König N, Rudolf M, Ulrich M, et al. (2003) A new sediment contact assay to assess particle-bound pollutants using zebrafish (Daniorerio) embryos. J Soils Sed 3: 197-207.

40. Scholz S, Kordes C, Hamann J, Gutzeit HO (2004) Induction of vitellogenin in vivo and in vitro in the model teleost medaka (Oryzias latipes): comparison of gene expression and protein levels. Mar Environ Res 57: 235-244.

41. Muncke J, Junghans M, Eggen RI (2007) Testing estrogenicity of known and novel (xeno-)estrogens in the MolDarT using developing zebrafish (Danio rerio). Environ Toxicol 22: 185-193.

42. Lai KM, Johnson KL, Scrimshaw MD, Lester JN (2000) Binding of waterborne steroid estrogens to solid phases in river and estuarine systems. Environ SciTechnol 34: 3890-3894. 
Citation: Sahoo TP, Oikari A (2013) Use of Early Juvenile Zebrafish Danio Rerio for In-Vivo Assessment of Endocrine Modulation by Xenoestrogens. J Environ Anal Toxicol 4: 202. doi: 10.4172/2161-0525.1000202

43. Kazeto $Y$, ljiri S, Place AR, Zohar Y, Trant JM (2001) The 5'-flanking regions of CYP19A1 and CYP19A2 in zebrafish. Biochem Biophys Res Commun 288 503-508.

44. Tong SK, Mouriec K, Kuo MW, Pellegrini E, Gueguen MM, et al. (2009) A cyp19a1b-gfp (aromatase B) transgenic zebrafish line that expresses GFP in radial glial cells. Genesis 47: 67-73

45. Brion F, Le Page Y, Piccini B, Cardoso O, Tong SK, et al. (2012) Screening estrogenic activities of chemicals or mixtures in vivo using transgenic (cyp19a1b-GFP) zebrafish embryos. PLoS One 7: e36069.

46. Lyssimachou A, Jenssen BM, Arukwe A (2006) Brain cytochrome P450 aromatase gene isoforms and activity levels in Atlantic salmon after waterborne exposure to nominal environmental concentrations of the pharmaceutical ethynylestradiol and antifoulant tributyltin. Toxicol Sci 91: 82-92.

47. Lee YM, Seo JS, Kim IC, Yoon YD, Lee JS (2006) Endocrine disrupting chemicals (bisphenol A, 4-nonylphenol, 4-tert-octylphenol) modulate expression of two distinct cytochrome P450 aromatase genes differently in gender types of the hermaphroditic fish Rivulus marmoratus. Biochem Biophys Res Commun 345: 894-903.

48. Melo AC, Ramsdell JS (2001) Sexual dimorphism of brain aromatase activity in medaka: induction of a female phenotype by estradiol. Environ Health Perspect 109: 257-264.

49. Sawyer SJ, Gerstner KA, Callard GV (2006) Real-time PCR analysis of cytochrome P450 aromatase expression in zebrafish: gene specific tissue distribution, sex differences, developmental programming, and estrogen regulation. Gen Comp Endocrinol 147: 108-117.

50. Muncke J, Eggen RI (2006) Vitellogenin 1 mRNA as an early molecular biomarker for endocrine disruption in developing zebrafish (Danio rerio). Environ Toxicol Chem 25: 2734-2741.

51. Kallivretaki E, Eggen R, Neuhauss S, Alberti M, Kausch U, et al. (2006) Aromatase in zebrafish: a potential target for endocrine disrupting chemicals. Mar Environ Res 62 Suppl: S187-190.

52. Kazeto Y, Goto-Kazeto R, Place AR, Trant JM (2003) Aromatase expression in zebrafish and channel catfish brains: changes in transcript abundance associated with the reproductive cycle and exposure to endocrine disrupting chemicals. Fish Physiol Biochem 28: 29-32.

53. Ruggeri B, Ubaldi M, Lourdusamy A, Soverchia L, Ciccocioppo R, et al. (2008)
Variation of the genetic expression pattern after exposure to estradiol-17beta and 4-nonylphenol in male zebrafish (Danio rerio). Gen Comp Endocrinol 158 138-144.

54. Vosges M, Kah O, Hinfray N, Chadili E, Le Page Y, et al. (2012) 17îtEthinylestradiol and nonylphenol affect the development of forebrain $\mathrm{GnRH}$ neurons through an estrogen receptors-dependent pathway. Reprod Toxicol 33: 198-204.

55. Gray MA, Metcalfe CD (1997) Induction of testis-ova in Japanese medaka (Oryziaslatipes) exposed to p-nonylphenol. Environ Toxicol Chem 16: 1082 1086

56. Harries JE, Runnalls T, Hill E, Harris CA, Maddix S, et al. (2000) Development of a reproductive performance test for endocrine disrupting chemicals using pair-breeding fathead minnows (Pimephales promelas). Environ Sci Technol 34: 3003-3011.

57. Preuss TG, Gehrhardt J, Schirmer K, Coors A, Rubach M, et al. (2006) Nonylpheno isomers differ in estrogenic activity. Environ Sci Technol 40: 5147-5153.

58. Cravedi JP, Zalko D (2005) Metabolic fate of nonylphenols and related phenolic compounds in fish. In: Biochemistry and Molecular Biology of Fishes, Environmental Toxicology6: 153-169.

59. Koger CS, Teh SJ, Hinton DE (2000) Determining the sensitive developmenta stages of intersex induction in medaka (Oryzias latipes) exposed to 17 betaestradiol or testosterone. Mar Environ Res 50: 201-206.

60. Takahashi H (1977) Juvenile hermaphroditism in the zebra?sh (Brachydanio rerio). Bulletin of the Faculty of Fisheries, Hokkaido University 28: 57-65.

61. Chen H, Hu J, Yang J, Wang Y, Xu H, et al. (2010) Generation of a fluorescent transgenic zebrafish for detection of environmental estrogens. Aquat Toxicol 96: 53-61.

62. Nakamura M, Kobayashi T, Chang XT, Nagahama Y (1998) Gonadal sex differentiation in teleost fish. J Exp Zool 281: 362-372.

63. Piferrer F, Zanuy S, Carrillo M, Solar II, Devlin RH, et al. (1994) Brief treatment with an aromatase inhibitor during sex differentiation causes chromosomally female salmon to develop as normal, functional males. J Exp Zool 270: 255262.

64. Fenske M, Segner $\mathrm{H}$ (2004) Aromatase modulation alters gonadal differentiation in developing zebrafish (Danio rerio). Aquat Toxicol 67: 105-126.
Citation: Sahoo TP, Oikari A (2013) Use of Early Juvenile Zebrafish Danio Rerio for In-Vivo Assessment of Endocrine Modulation by Xenoestrogens. J Environ Anal Toxicol 4: 202. doi: 10.4172/2161-0525.1000202
Submit your next manuscript and get advantages of OMICS Group submissions

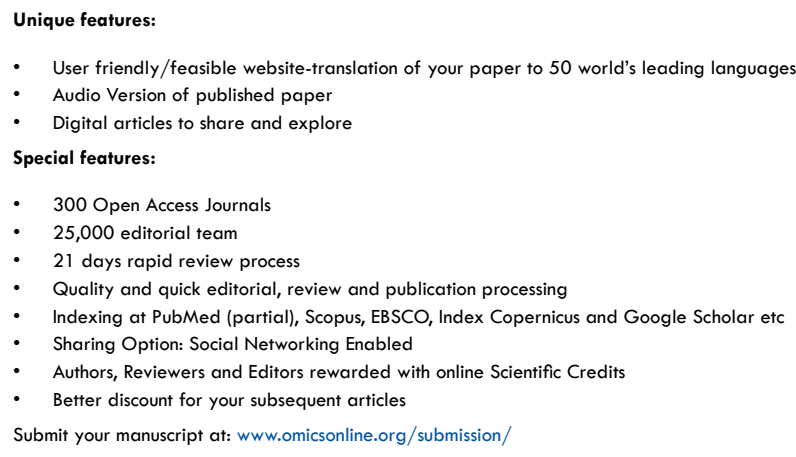




\section{Supplementary material}

Use of early juvenile zebrafish Danio rerio for in vivo assessment of endocrine modulation by xenoestrogens

Contents:

1. Chemical analyses of water samples

2. Tables S1, S2 and S3

3. Figure $\mathrm{S} 1$

4. Tables S1 and S2 were created using Word

5. Table S3 and Figure S1 are TIFF files created using CorelDraw (version 12.0)

\section{Chemical analysis of water samples}

\subsection{Solid-phase extraction (SPE) of water samples}

Briefly, Oasis SPE cartridges (Oasis HLB, 3cc, $60 \mathrm{mg}$ ) were conditioned with $3 \mathrm{~mL}$ methyl-t-butyl ether (MTBE), subsequently rinsed with $3 \mathrm{~mL}$ methanol and $3 \mathrm{~mL}$ ultrapure water. Water samples $(1000 \mathrm{~mL})$, containing internal standard (d4-EE2), were acidified to $\mathrm{pH} 3$ before loading onto the cartridges. The extraction was managed as a dropwise outflow, where after the cartridge was re-equilibrated with $3 \mathrm{~mL}$ ultrapure water. The elution solvent, $10 \%$ $\mathrm{MeOH}$ in MTBE $(3 \times 2 \mathrm{~mL})$, was added and allowed to react with the analytes on the sorbents and ultimately eluted into collection tubes. The contents were evaporated to dryness while tubes were immersed in a water bath (ca. 50 ${ }^{\circ} \mathrm{C}$ ) under a gentle nitrogen flow. Samples were reconstituted in $200 \mu \mathrm{L}$ 50:50 (v/v) acetonitrile: $2.5 \mathrm{mM}$ ammonium acetate in water $(\mathrm{pH} 3)$.

\subsection{GC-MS analysis of EE2}

The dried residues were treated (silylated) with $50 \mu \mathrm{L}$ BSTFA $(+1 \% \mathrm{TMCS})$ and $50 \mu \mathrm{L}$ pyridine, incubated at $70{ }^{\circ} \mathrm{C}$ for $30 \mathrm{~min}$, where after cooled and evaporated to dryness with nitrogen stream. Finally, hexane $(100 \mu \mathrm{L})$ was added, followed by transferring the contents to auto sampler vials for the GC-MS, performed with HP 6890 gas chromatograph (Hewlett-Packard, Walbronn, Germany) equipped with HP 5973 mass selective detector (HewlettPackard, Palo Alto, CA, USA). A HP-5 capillary column $(30 \mathrm{~m} \times 0.25 \mathrm{~mm} \times 0.25 \mu \mathrm{m})$ was used with helium as the carrier gas by a rate of $0.9 \mathrm{~mL} \mathrm{~min}^{-1}$. The column temperature was programmed to increase from $120{ }^{\circ} \mathrm{C}$ to $190{ }^{\circ} \mathrm{C}$ at the rate of $8{ }^{\circ} \mathrm{C} \min ^{-1}, 190{ }^{\circ} \mathrm{C}$ to $240{ }^{\circ} \mathrm{C}$ at $2{ }^{\circ} \mathrm{C} \mathrm{min}^{-1}, 240{ }^{\circ} \mathrm{C}$ to $280{ }^{\circ} \mathrm{C}$ at $10{ }^{\circ} \mathrm{C} \mathrm{min}^{-1}$ (maintained for $8 \mathrm{~min}$ ), and $280{ }^{\circ} \mathrm{C}$ to $290{ }^{\circ} \mathrm{C}$ at $10{ }^{\circ} \mathrm{C} \min ^{-1}$ (maintained for $20 \mathrm{~min}$ ). The MS was operated in selective ion monitoring mode, and identification was made based on retention time and mass spectra of pure standards.

\subsection{LC-MS /MS analysis of BPA, NP and OP}

Separation with a reverse phase C18 column (Waters XBridge $3.5 \mu \mathrm{m}, 2.1 \times 100 \mathrm{~mm}$ with $3.5 \mu \mathrm{m}, 2.1 \times 10 \mathrm{~mm}$ guard column) was performed with Waters Alliance 2795 (MA, USA) LC consisting of tertiary pump, vacuum degasser, auto sampler and column oven. The column temperature was set to $30{ }^{\circ} \mathrm{C}$ and that of auto sampler to $20{ }^{\circ} \mathrm{C}$. The injection volume was $20 \mu \mathrm{L}$. The determination of target compounds was performed in negative ion electrospray mode (ESI-) and a Quattro Micro triple quadrupole mass spectrometer (MS/MS) (Waters, MA, USA) with 
electrospray interface was used as detector. The mobile phases consisted of $\mathrm{MeOH}$ (A) and distilled water (B) with a flow of $0.2 \mathrm{~mL} \mathrm{~min}^{-1}$. The gradient of $\mathrm{A}$ was raised to $100 \%$ over $10 \mathrm{~min}$, phase proportion maintained for $8 \mathrm{~min}$ (10-18 $\mathrm{min}$ ), and lowered back to $60 \%$ over $2 \mathrm{~min}$. The column was equilibrated for three $\min (20-23 \mathrm{~min})$ prior to the next injection.

\begin{tabular}{|l|l|l|l|l|l|}
\hline Compound & Fw & Precursor ion $\mathrm{m} / \mathrm{z}$ & Product ions $\mathrm{m} / \mathrm{z}$ & Cone voltage (V) & Collision energy (eV) \\
\hline BPA & 228.3 & 227.1 & $133.1,212.0$ & 39 & 21 \\
\hline $\begin{array}{l}\text { d16- } \\
\text { BPA(IS) }\end{array}$ & 244.06 & 241.1 & $142.1,223.1$ & 41 & 28 \\
\hline NP & 220.4 & 219.3 & $106.0,118.7$ & 40 & 34 \\
\hline OP & 206.3 & 205 & 133 & 38 & 27 \\
\hline
\end{tabular}

Table S1: Acquisition parameters of mass spectrometry for target compounds and corresponding internal standard (IS; d16-BPA) used in this study.

\begin{tabular}{|c|c|c|c|}
\hline Gene & Primer sequences $\left(5^{\prime}-3^{\prime}\right)$ & Size (bp) & Genbank accession \\
\hline \multirow[b]{2}{*}{$\beta$-actin } & Forward-AAGAGCTATGAGCTGCCTGA & \multirow[b]{2}{*}{108} & \multirow[b]{2}{*}{ AF057040.1 } \\
\hline & Reverse-ACCGCAAGATTCCATACCCA & & \\
\hline \multirow[b]{2}{*}{ cypl9alb } & Forward-TGGACGCATGCATAAGACAG & \multirow[b]{2}{*}{104} & \multirow[b]{2}{*}{ AF226619.1 } \\
\hline & Reverse-CACAACCGAATGGCTGGAA & & \\
\hline \multirow[b]{2}{*}{ efla } & Forward-AAACATGGGCTGGTTCAAGG & \multirow[b]{2}{*}{87} & \multirow[b]{2}{*}{ AY422992.1 } \\
\hline & Reverse-ATGGCATCAAGGGCATCAAG & & \\
\hline \multirow[b]{2}{*}{ cypllal } & Forward-GCCTGGAAGACTGATAGGATGA & \multirow[b]{2}{*}{114} & \multirow[b]{2}{*}{ AF527755.1 } \\
\hline & Reverse-GTTGACACGAGCCACAAAGT & & \\
\hline \multirow[b]{2}{*}{ star } & Forward-TGTAAGGGCTGAGAATGG & \multirow[b]{2}{*}{133} & \multirow[b]{2}{*}{ NM_131663.1 } \\
\hline & Reverse-TACTCGGTTGATGACAGTT & & \\
\hline \multirow[b]{2}{*}{ vtgl } & Forward-GCTTTGCCTATTCCCACATC & \multirow[b]{2}{*}{136} & \multirow[b]{2}{*}{ NM_001044897.2 } \\
\hline & Reverse-GCTCTGCTGTAACGGTAGT & & \\
\hline \multirow[b]{2}{*}{ hsd3bl } & Forward-AGCCCATTCTGCCCATCTTT & \multirow[b]{2}{*}{120} & \multirow[b]{2}{*}{ AY279108.1 } \\
\hline & Reverse-CCATGGTCACTAGCTGCCTATT & & \\
\hline
\end{tabular}

Table S2: Primer pair sequences, amplicon sizes, and accession numbers for genes investigated in this study ( $\beta$ actin, beta-actin; efla, elongation factor 1a; vtg1, vitellogenin isoform 1; cyp19alb, brain aromatase; star, steroidogenic acute regulatory protein; cypl lal, P450 side chain cleavage; hsd3bl, 3-beta-hydroxysteroid dehydrogenase). Note the primer design for VTG1 was custom ordered from Sigma-Aldrich. 


\begin{tabular}{|l|l|l|l|l|l|l|l|l|}
\hline \multicolumn{2}{|l|}{ EE2 $\left(\mathrm{ng} \mathrm{L}^{-1}\right)$} & \multicolumn{2}{l|}{ BPA $\left(\mu \mathrm{g} \mathrm{L}^{-1}\right)$} & \multicolumn{2}{l|}{ OP $\left(\mu \mathrm{g} \mathrm{L}^{-1}\right)$} \\
\hline Nominal & Measured & $\%$ Nominal & Nominal & Measured & $\%$ Nominal & Nominal & Measured & \% Nominal \\
\hline 5 & $1.7 \pm 0.6$ & 34 & 100 & $92 \pm 11$ & 92 & 10 & $3.9 \pm 1.2$ & 39 \\
\hline 25 & $10.8 \pm 0.1$ & 43 & 500 & $410 \pm 40$ & 82 & 50 & $20.2 \pm 8.0$ & 40 \\
\hline 50 & $28.3 \pm 6.4$ & 57 & 1000 & $808 \pm 307$ & 81 & 100 & $45.2 \pm 8.7$ & 45 \\
\hline
\end{tabular}

Table S3: Nominal and measured concentrations of EE2, BPA and OP in exposure series I and II. Measured concentrations (mean $\pm \mathrm{sd}$ ) were determined for exposure samples collected at two time points (days 1 and 4 ) along the five-day exposure period.

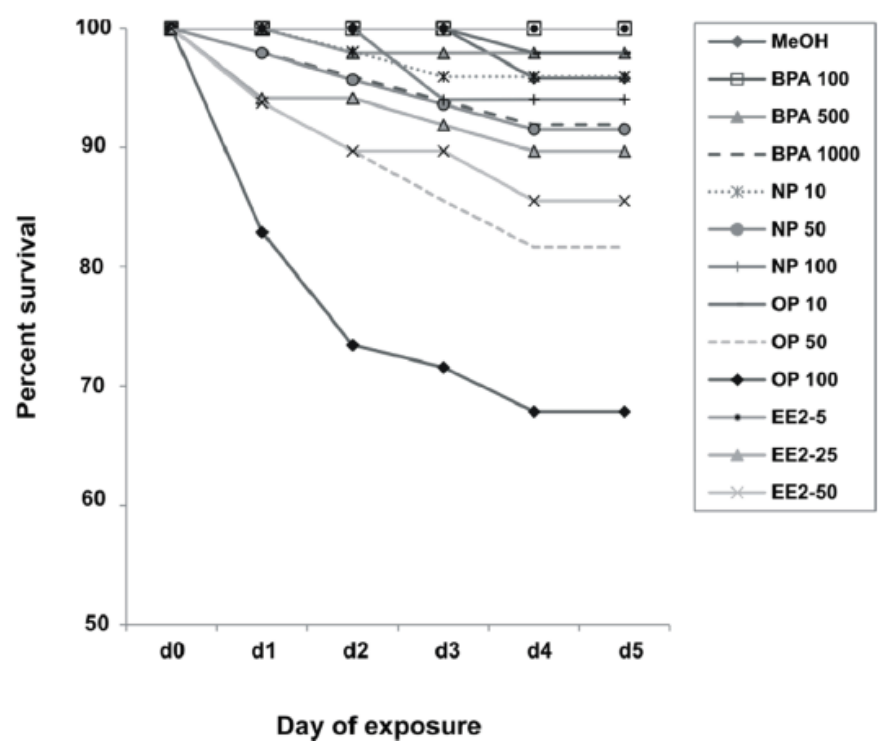

Figure S1: Survival plot of $20 \mathrm{dpf} Z F$ exposed to xenoestrogens in Exposure I. The data represent mean of three replicates per experimental and control groups each containing $n=25$ fish. Note experimental groups exposed to OP (50 and $100 \mu \mathrm{g} \mathrm{L}^{-1}$ ) and EE2 (50 $\left.\mathrm{ng} \mathrm{L}^{-1}\right)$ showed mortality (\%) at 18, 32 and 15 respectively. 